\title{
Conductivity and Complex Electrical Formalism of the Iron-Doped PbLaTiO 3 Ferroelectric Relaxor
}

\author{
Lhaj Hachemi Omari and Salaheddine Sayouri \\ Laboratoire de Physique Théorique et Appliquée, Département de Physique, Faculté des Sciences-DM, 30000 Fès, Morocco \\ Correspondence should be addressed to Salaheddine Sayouri; ssayouri@yahoo.com
}

Received 17 December 2012; Accepted 29 January 2013

Academic Editors: D. Chicot, M. Martino, A. O. Neto, D. Sands, and H. Zhang

Copyright (C) 2013 L. H. Omari and S. Sayouri. This is an open access article distributed under the Creative Commons Attribution License, which permits unrestricted use, distribution, and reproduction in any medium, provided the original work is properly cited.

Polycrystalline perovskite nanomaterials $\left(\mathrm{Pb}_{0.88} \mathrm{La}_{0.12}\right)\left(\mathrm{Fe}_{x} \mathrm{Ti}_{1-x}\right)_{0.97} \mathrm{O}_{3}$ were prepared by sol-gel reaction method. The crystal structure examined by X-ray powder diffraction indicates that the material was single phase with pseudocubic structure. EDX and SEM studies were carried out in order to evaluate the quality and purity of the compounds. The crystal symmetry, space group, and unit cell dimensions were determined from Cell-Ref software, whereas crystallite size was estimated from Scherrer's formula. A correlation between grain size and diffuse character for the samples has been observed. Dielectric studies exhibit a diffuse phase transition characterized by a strong temperature and frequency dispersion of the permittivity and a relaxor behaviour. We have observed that dielectric constant decreases and ac conductivity increases with the frequency. The dielectric relaxation has been modeled using the Curie-Weiss and modified Curie-Weiss laws. The calculated activation energy $E_{a}$ for $x=1 \%$ and $3 \%$ was between $0.91-2.1 \mathrm{eV}$ and $0.425-1.08 \mathrm{eV}$, respectively. The relaxation times were estimated from the Arrhenius law.

\section{Introduction}

Perovskite-structured ferroelectric crystals have the general formula $\mathrm{ABO}_{3}$, where $\mathrm{A}$ is mono- or divalent ion with large radius and low valence, while $B$ is a tetra- or pentavalent ion with small radius and high valence [1]. Among the perovskitetype oxides, titanate ceramics have been considered as interesting materials for room temperature applications, mainly due to their interesting dielectric properties [2]. Lead titanate $\left(\mathrm{PbTiO}_{3}\right)$, with a very high Curie temperature of $490^{\circ} \mathrm{C}$, belongs to a most important perovskite family due to its remarkable ferroelectric and piezoelectric features in polycrystalline form [3]. The phase transition behavior in $\mathrm{PbTiO}_{3}$ single crystal is relatively simple; it exhibits a single transition from paraelectric with cubic phase to ferroelectric with tetragonal phase [4]. It has been observed that substitution of any suitable ions at the $\mathrm{Pb}$ and/or Ti site of lead titanate results in substantial modification in their electrical properties so as to make them suitable for a wide variety of industrial applications. The doping subsistent can either occupy A-site, B-site, or both, as a donor or an acceptor, based on chemical valence with respect to the original ions. The electrical properties of the ceramics are a result of different contributions from various components and processes in the materials. The charge transport can take place via modes, such as dipole reorientation, charge displacement, and space charge formalism [5]. It is wellknown that transition ions, having partially filled d-orbital like $\mathrm{Mn}^{3+}, \mathrm{Fe}^{3+}$ ions, are generally used at B-site. Fluctuation of the oxidation state of these ions results in the formation of oxygen ion vacancies which causes thermally activated conduction. Thus, most of the multiferroic materials show high leakage current and low ferroelectric polarization [6]. In order to improve the ferroelectric properties, lanthanum (La) has been introduced. An appropriate and optimum amount of La lowers the leakage current and provides good bistable polarization, which is a primary requirement for nonvolatile random access memory (NVRAM) applications [7].

Sol-gel process has been used to synthesize nanocrystalline ferroelectrics. This method offers several advantages (such as gaining time, saving energy, and better homogeneity) more than the other conventional methods. It was shown 


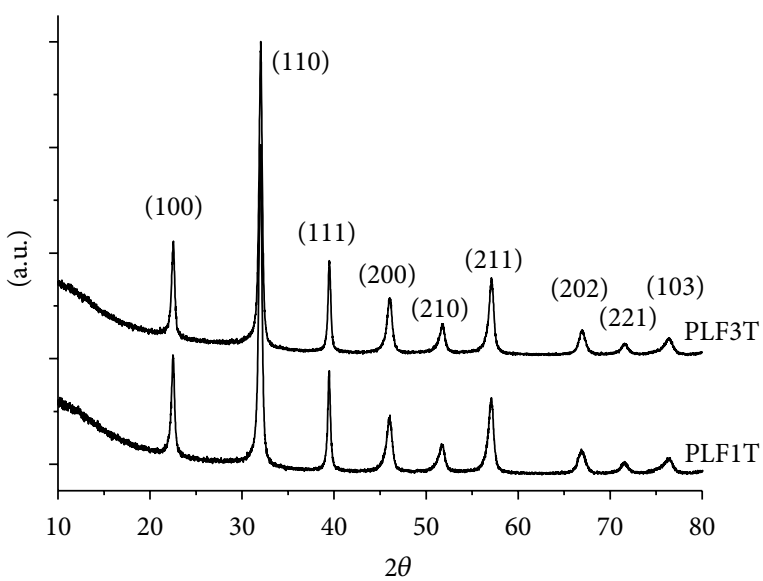

FIGURE 1: Room temperature XRD pattern of $\mathrm{Pb}_{0.88} \mathrm{La}_{0.12} \mathrm{Fe}_{x} \mathrm{Ti}_{1-x} \mathrm{O}_{3}$ $(x=0.01$ or 0.03$)$ compounds.

that the crystallization of PLFT occurred at $500^{\circ} \mathrm{C}$ [8]; this temperature is inferior to that reported for the same composition prepared by the traditional solid-state reaction technique [9]. Complex impedance spectroscopy (CIS) is a well-known technique to investigate electrical properties of materials. It describes the electrical processes occurring in a system on application of an AC signal as input perturbation [10]. It is a useful technique with enormous potential and possibilities not only for investigation but also for characterization of the electrical and electrochemical properties of electroceramics materials. It has also a great ability to analyze the relaxation phenomenon occurring in the material, whose time constants range over several orders of magnitude [11]. A much more profound analysis is possible by combining the impedance analysis with use of the complex electrical formalism [12].

\section{Experiment}

In this work, lanthanum $\left(\mathrm{La}^{3+}\right)$ and iron $\left(\mathrm{Fe}^{3+}\right)$ modified lead titanate (PLFT) ceramics, with a general formula $\mathrm{Pb}_{0.88} \mathrm{La}_{0.12} \mathrm{Fe}_{x} \mathrm{Ti}_{1-x} \mathrm{O}_{3}(\mathrm{PL} 12 \mathrm{~F} x \mathrm{~T})(x=0.01,0.03)$, were synthesized from high purity precursors by the sol-gel reaction method [13]. Then, the powders were calcinated at optimized temperature $\left(700^{\circ} \mathrm{C}\right)$ and time $(2 \mathrm{~h})$ in a programmable oven. The formation of single-phase compounds was confirmed by XRD. The calcinated powders were used to make cylindrical pellets using a hydraulic press at a pressure of $5 \mathrm{kbar}$. These pellets were sintered at the optimized temperature $\left(1100^{\circ} \mathrm{C}\right)$ for $2 \mathrm{~h}$ in an air atmosphere. Electrical measurements were carried out at an input signal level of $1 \mathrm{~V}$ in a wide temperature range of $50^{\circ} \mathrm{C}-600^{\circ} \mathrm{C}$ using a computer controlled impedance analyzer, in the frequency range from $1 \mathrm{kHz}$ to $1 \mathrm{MHz}$.

\section{Results and Discussion}

Figure 1 shows the X-ray diffraction patterns collected at room temperature of PL12FxT ( $x=1 \%$ and $3 \%$ ) powders. Lead titanate is a displacive type ferroelectric compound, having tetragonal structure with very large lattice distortion

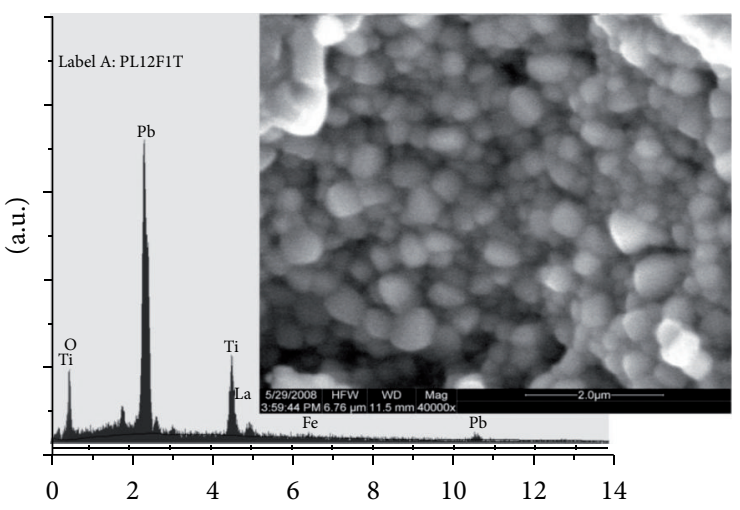

(a)

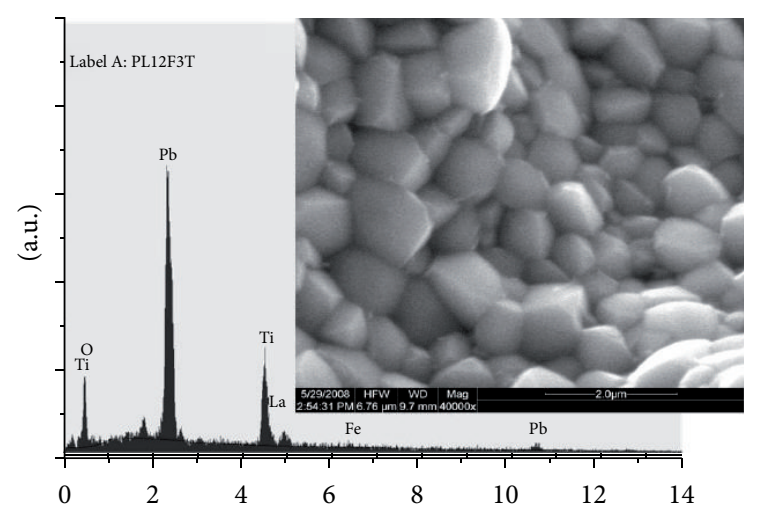

(b)

FIGURE 2: SEM micrographs of the PL12F $x$ T ( $x=1 \%$ in (a) and $3 \%$ in (b)) ceramics sintered in $1200^{\circ} \mathrm{C}$ for $2 \mathrm{~h}$ and their EDX spectra.

from a cubic structure [14]. All the peaks of the XRD patterns of the PLFT ceramics were indexed and the lattice parameters were determined in various crystal systems, using a computer program (Cell-Ref). Since the ionic radius of $\mathrm{Fe}^{3+}$ is smaller than that of $\mathrm{Ti}^{4+}$, the tetragonal ratio (c/a) and the unit cell volume decrease with increasing $\mathrm{Fe}$ content. The samples crystallized completely without the presence of peaks corresponding to reactant oxides or any other secondary phases and exhibited a diffractogram characteristic of a single-phase compound that has a pseudocubic structure belonging to the space group $\mathrm{Pm}-3 \mathrm{~m}$, which is consistent with our previous published papers $[15,16]$ and which demonstrates that the crystallization process occurred between 400 and $500^{\circ} \mathrm{C}$. The lattice parameters and volume cell were estimated and gathered in Table 1.

Figure 2 shows the SEM micrographs of the PL12F $x$ T ceramics $(x=1 \%$ in Figure 2(a) and $x=3 \%$ in Figure 2(b)) annealed at $1100^{\circ} \mathrm{C}$ for $2 \mathrm{~h}$. The grains present an average size of $200 \mathrm{~nm}$ for $x=1 \%$ and of $400 \mathrm{~nm}$ for $x=3 \%$. Analysis of the SEM micrographs suggests that larger particles can be formed by a single particle or by an agglomeration process of smaller particles. The average grain sizes determined from the analysis of the XRD patterns of PL12F1T and PL12F3T samples were $24.95 \mathrm{~nm}$ and $33.25 \mathrm{~nm}$, respectively. Table 1 shows the crystallite size values of the two samples evaluated 
TABLE 1: Cell parameters and Vogel-Fulcher fitting parameters of PL12F $x$ T.

\begin{tabular}{llllcccc}
\hline PL12F $x$ T & $a(\AA)$ & $c(\AA)$ & $V\left(\AA^{3}\right)$ & $g \cdot s(\mathrm{~nm})$ & $E_{a \tau c}(\mathrm{eV})$ & $\tau_{o}(\mathrm{~s})$ & $f_{0}(\mathrm{~Hz})$ \\
\hline$x=1 \%$ & 3,944 & 3,948 & 61,412 & 24,95233 & 0,485 & $6,7510^{-14}$ & $1,48.10^{13}$ \\
$x=3 \%$ & 3,936 & 3,977 & 61,627 & 33,25656 & 0,89 & $5,5510^{-13}$ & $1,8.10^{12}$ \\
\hline
\end{tabular}

with the help of Scherrer's formula [17] using the full width at half height of (1.1.1) peaks from the XRD patterns recorded for the two samples. The average crystallite size was calculated using the full width at half height of 1.1.1 peaks from the XRD patterns recorded for the two samples. The average crystallite size is smaller than the average grain size evaluated from the SEM measurements, meaning that each particle observed by SEM imaging consists of several coherent diffracting domains and suggesting that high temperature and sintering time favor the grain growth, leading to micrometric grain sizes, which is in agreement with previous studies $[13,15]$. Moreover, it is seen that the grain size of PLFT ceramics increases with an increase of Fe content. Figure 2 shows the dispersive energy $\mathrm{X}$-ray spectroscopy (EDX) spectra for the samples with $x=$ $1 \%$ and $3 \%$, which indicates the arbitrarily selected region containing $\mathrm{Pb}, \mathrm{La}, \mathrm{Fe}, \mathrm{Ti}$, and $\mathrm{O}$.

The temperature dependence of the dielectric constant $\left(\varepsilon_{r}\right)$ of the PLFT specimens at different frequencies is shown in Figure 3(a). As expected, dielectric measurements show a frequency dispersion at the temperature of the maximum of the dielectric curves $\left(T_{m}=263^{\circ} \mathrm{C}\right.$ for $x=1 \%$ and $T_{m}=$ $265^{\circ} \mathrm{C}$ for $x=3 \%$ at $1 \mathrm{kHz}$ ) allowing characterizing the samples as relaxor ferroelectric materials. Addition of $\mathrm{Fe}$ in PLT decreases the values of $\varepsilon_{r \text { max }}$, whereas the value of $T_{m}$ increases with an increase of Fe content. This may be due to the increase of translational symmetry and the size of polar regions. The neighboring ions are redistributed by the incorporation of Fe. The same behavior was observed with $\mathrm{La}$ modified NBT [18-20]. On the contrary, the increasing concentration of $\mathrm{Ca}$ on the B-site in the BCT-C ceramics results in suppressing greatly the dielectric peaks and decreasing the temperature $T_{m}[21]$. This result was attributed to the increase of the internal stress resulting from the lattice distortion due to the Ca occupancy of B-site in BCT-C ceramics [22]. The dielectric loss is reduced by the formation of $\mathrm{B}$-site Tivacancies in Fe modified PLT that inhibits the occurrence of $\mathrm{O}$-vacancies during high-temperature sintering process.

At higher temperatures, dispersion in the permittivity curves is observed in both real and imaginary parts. Furthermore, the dielectric curves of the samples are largely broadened indicating a higher degree of the diffuse character in the dielectric behavior at the transition, which became important with increasing the frequency. From previous published papers $[23,24]$ it is known that pure PLT ceramics act like a relaxor ferroelectric from $15 \%$ content in La [25]. The degree of relaxation behavior became important and larger with increasing iron concentration. This occurrence is difficult to observe due to dielectric dispersion that emerges at low frequencies around and above Curie temperature [26]. This is possibly related to the polarization mechanism associated with the thermally activated conduction of mobile ions and/or other defects [27]. Pure PL12FxT ceramics exhibit, at room temperature, a dielectric constant of 496,66 for $x=1 \%$ and 224,25 for $x=3 \%$, which increases its value, while the dielectric constant at the Curie temperature decreases with the increasing of iron concentration (Table 2). Our results clearly show that, in the case of nanostructured ceramic sample, even with the sample presenting a nanometric grain size, the polar long-range order is not respected and the domain structure is characterizing the relaxor ferroelectric compound with a diffuse phase transition. Moreover the increase in the grain size leads to a reduction from approximately 5000 to 2500 in the magnitude of the dielectric permittivity $\left(\varepsilon_{r \max }\right)$ at $T_{m}$. Dielectric losses of PL12F1T and PL12F3T are shown in Figure 3(b). It is observed that the values of $\tan \delta$ are very low (at approximately $50^{\circ} \mathrm{C}, \tan \delta$ at $1 \mathrm{kHz}$ is 0,275 and 0,569 for $1 \%$ and $3 \%$, resp.). Fe doping influences the increase of $\tan \delta$ at room temperature and at higher temperatures. Beyond the $T_{c}$, dielectric losses exhibit a significant increase due to the space charge polarization. Above Curie temperature the conductivity begins to dominate, influencing the $\tan \delta$ rise. It is well known that the dielectric constant of normal ferroelectrics follows the CurieWeiss law $(\mathrm{CW})$ :

$$
\frac{1}{\varepsilon_{r}}=\frac{T-T_{\mathrm{cw}}}{C},
$$

where $C$ is the CW constant and $T_{\mathrm{cw}}$ is the $\mathrm{CW}$ temperature [28]. If a material shows the normal ferroelectric behavior, it follows Curie-Weiss law above $T_{\mathrm{cw}}$. The linear fitting of all the data was found to be not exactly linear, confirming that the behavior of the two samples disagrees with Curie-Weiss law and hence it exhibits a diffuse phase transition (Figures 4(a) and 4(b)). The degree of deviation from the Curie-Weiss behavior could be given by $\Delta T_{m}$, where

$$
\Delta T_{m}=T_{m}-T_{\mathrm{cW}},
$$

where $T_{\mathrm{cw}}$ represents the temperature from which it starts to deviate from the Curie-Weiss law and $T_{m}$ denotes the temperature of the maximum of $\varepsilon_{r}$. It can be seen from Table 2 that $\Delta T_{m}$ increases with an increasing frequency.

Another parameter, which is used to characterize the degree of relaxation behavior in the frequency range from $1 \mathrm{kHz}$ to $1 \mathrm{MHz}$, is described [28] as

$$
\Delta T_{\text {relax }}=T_{m(\mathrm{HF})}-T_{m(\mathrm{LF})}
$$

(HF and LF stand for high and low frequencies, resp.). The value of $\Delta T_{\text {relax }}$ was determined for the PL12FxT ceramics as shown on Table 2 .

The above characterization, done on the basis of the Curie-Weiss law and the value of empirical parameters, like $\Delta T_{m}$ and $\Delta T_{\text {relax }}$, suggests that the permittivity of the PLFT 
TABLe 2: Physical properties of PL12F $x$ T.

\begin{tabular}{|c|c|c|c|c|c|c|c|c|}
\hline PL12F $x \mathrm{~T}$ & $f(\mathrm{MHz})$ & $T_{\mathrm{cw}}\left({ }^{\circ} \mathrm{C}\right)$ & $C\left(\times 10^{5}\right)$ & $\Delta T_{m}$ & $\Delta T_{\text {relax }}$ & $\gamma$ & $\delta$ & $E_{a}(\mathrm{eV})$ \\
\hline \multirow{7}{*}{$x=1 \%$} & 0.001 & 250 & 1,28 & 13 & 0 & 1.56 & 25.5 & 2.10 \\
\hline & 0.01 & 251 & 1,25 & 12 & $4 E-6$ & 1.58 & 26.16 & 2.08 \\
\hline & 0.05 & 253 & 1,22 & 10 & 1,78 & 1.76 & 32.7 & 2.01 \\
\hline & 0.1 & 248 & 1,27 & 15 & 6,81 & 1.84 & 39.45 & 1.73 \\
\hline & 0.2 & 249 & 1,25 & 14 & 19,11 & 1.77 & 50.7 & 1.4 \\
\hline & 0.4 & 228 & 1,45 & 35 & 36,22 & 1.86 & 67 & 1.06 \\
\hline & 0.6 & 210 & 1,58 & 53 & 46,74 & 1.85 & 79.63 & 0.91 \\
\hline \multirow{7}{*}{$x=3 \%$} & 0.001 & 232 & 1,01 & 33 & 0 & 1.43 & 29.47 & 1.108 \\
\hline & 0.01 & 228 & 0,96 & 37 & 12,71 & 1.78 & 53.3 & 0.81 \\
\hline & 0.05 & 210 & 1,06 & 55 & 28,78 & 1.63 & 79.78 & 0.73 \\
\hline & 0.1 & 198 & 1,08 & 67 & 46,02 & 1.74 & 91.24 & 0.61 \\
\hline & 0.2 & 116 & 1,47 & 149 & 71,13 & 1.97 & 119.5 & 0.503 \\
\hline & 0.4 & 128 & 2,12 & 137 & 89,38 & 1.77 & 132.6 & 0.452 \\
\hline & 0.6 & 172 & 2,68 & 93 & 100,17 & 1.84 & 162.17 & 0.425 \\
\hline
\end{tabular}

ceramics follows the Curie-Weiss law only at temperatures much higher than $T_{m}$. Thus the large deviation from the Curie-Weiss behavior and the large relaxation temperature $\Delta T_{\text {relax }}$ suggest that PLFT is a relaxor ferroelectric. It indicates that a very little amount in $\mathrm{Fe}^{3+}$, substituted in a PLT-based ceramic, can induce the relaxor behavior.

The following modified CW law is usually used to describe the $\varepsilon_{r}$ peak behavior at high temperature and the diffuse character of the phase transition $[29,30]$ :

$$
\frac{1}{\varepsilon_{r}}=\frac{1}{\varepsilon_{r m}}\left(1+\frac{\left(T-T_{m}\right)^{\gamma}}{2 \delta^{\gamma}}\right),
$$

where $\delta$ describes the diffuse character of the material. When $\gamma=1$ the material is described as a normal ferroelectric, and a relaxor when $\gamma=2$, which corresponds to the polar domains fluctuations. The diffused phase transition is observed in the two samples, as exemplified by the broadening of the dielectric peak (Figure 3(a)). Therefore, we have studied the nature of diffusivity. A plot of $\ln \left[2\left(\left(\varepsilon_{r m} / \varepsilon_{r}\right)-1\right)\right]$ as a function of $\ln \left(T-T_{m}\right)$ at different frequencies is presented in Figures 4(c) and 4(d) for PL12FxT ceramics. The obtained values of $\gamma$ (from experimental data at various frequencies) are shown in Table 2. It is also clear that with the increase of iron concentration the diffusivity is more evidenced. From fitting the curves (Figures 4(c) and 4(d)), slopes are obtained for different frequencies and values of $\gamma$ and $\delta$ are calculated. The value of $\gamma$ at $10 \mathrm{kHz}$ is 1.48 and 1.62 for $1 \%$ and $3 \%$ content in $\mathrm{Fe}$, respectively, which confirms the diffuse phase transition in PL12FT system. In addition, high values of $\gamma$ and $\delta$, for high frequencies, demonstrate that the degree of relaxation and diffuse character are very important (Figures $4(\mathrm{e})$ and $4(\mathrm{f})$ ). It is observed that $\varepsilon(T)$ can be fitted quite well at low- and hightemperature regions, but still the fitting works better at $T>$ $T_{m}$. One can notice that the increase of $\delta$ with the increase of Fe concentration in the PL12FxT indicates an increase of the degree of the diffuse character of the dielectric peak. In general, the broadening or diffusivity occurs mainly because of the compositional fluctuations, due to Fe doping and to the structural short-range disorder in the arrangement of cations in one or more crystallographic sites of the structure.

The conductivity of the samples was estimated from the dielectric parameters. As long as the pure charge transport mechanism is the major contributor to the loss mechanisms, the ac conductivity may be calculated using the relation $\sigma=$ $\omega \varepsilon_{r} \varepsilon_{o} \tan \delta[31,32]$, in which $\varepsilon_{0}$ is the vacuum dielectric constant and $\omega$ is the angular frequency. In reality, loss tangent is due to the culmination of a variety of loss mechanisms, and distinguishing between all these contributions remains a formidable task. The conductivity for all the samples was estimated over a certain temperature range. The total conductivity follows the universal law

$$
\sigma(\omega)=\sigma_{\mathrm{dc}}+\sigma_{\mathrm{ac}}(\omega)
$$

where $\sigma_{\mathrm{dc}}$ is the dc conductivity and $\sigma_{\mathrm{ac}}$ is the ac part of the conductivity. From the obtained values of $\sigma_{\mathrm{dc}}$ at different temperatures, one can calculate the activation energy $E_{a \mathrm{dc}}$ according to Arrhenius law [33, 34]:

$$
\sigma_{\mathrm{dc}}=\sigma_{0} \exp \left(-\frac{E_{a \mathrm{dc}}}{k_{B} T}\right) .
$$

From the plot of $\ln \left(\sigma_{\mathrm{dc}}\right)$ versus $10^{3} / T$ (Figure 5), the activation energy $\left(E_{a}\right)$ of the samples was calculated at a temperature in the ferroelectric region near the $T_{\max }$, where the losses are relatively low. Values of activation energy $E_{a}$ are also given in Table 2. In the PL12F3T ceramic the decrease in the activation energy as compared with the PL12F1T may be imputed to oxygen vacancies. With further increase of iron concentration, $E_{a}$ decreases due to the increase of conducting species in the samples. For two doped samples the Arrhenius plots of conductivity were linear over a temperature range of $250-260^{\circ} \mathrm{C}$. In our investigation the conductivity increases with a temperature increase due to thermal activation of conducting species in the samples.

Electrical behavior of the compounds has been characterized over wide temperature and frequency ranges by using ac impedance methods as the semiempirical complex 

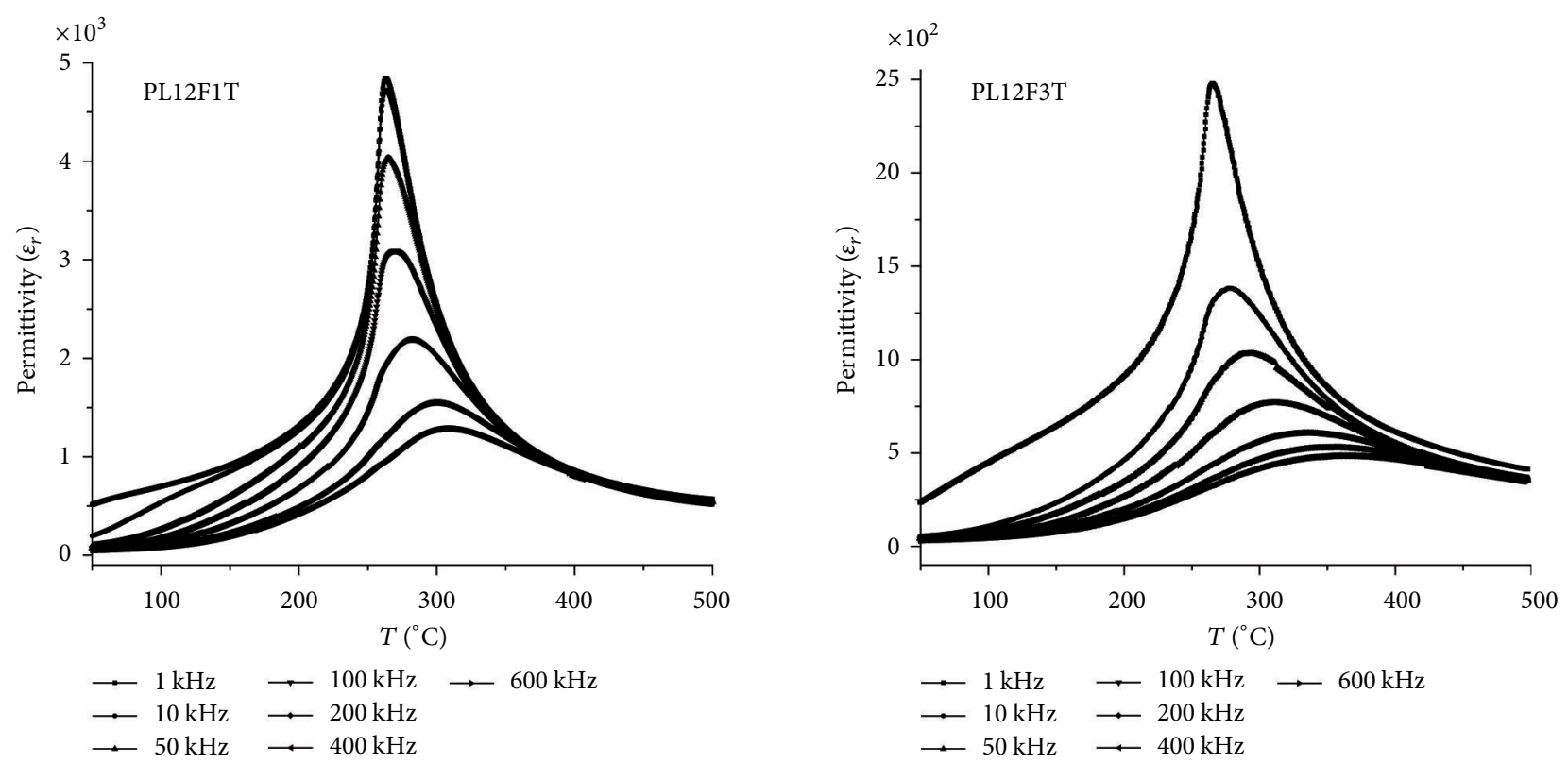

(a)
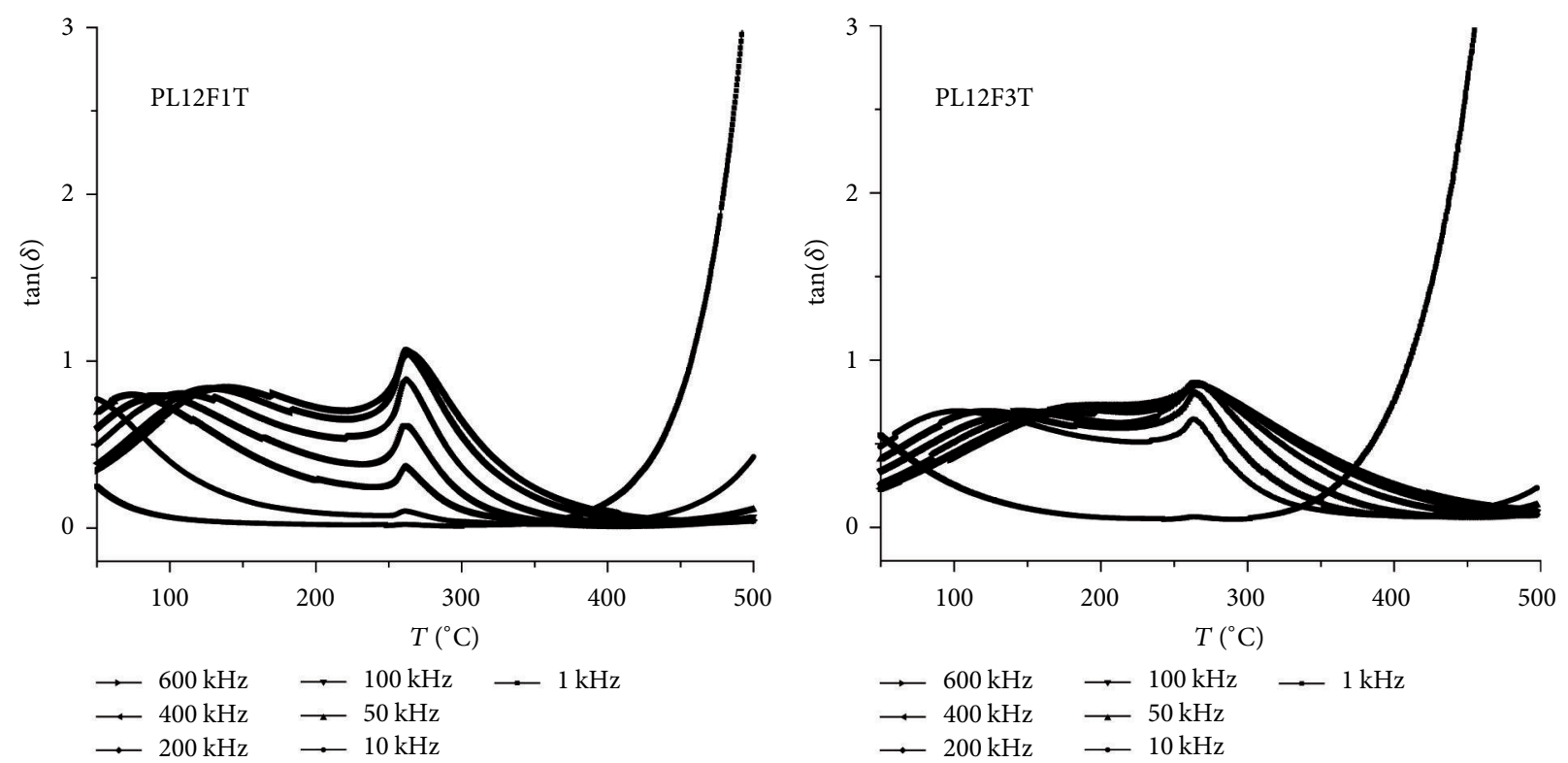

(b)

Figure 3: Temperature dependence of the dielectric constant (Figure 3(a)) and loss (Figure 3(b)) for PLFT ceramics measured at various frequencies.

Cole-Cole equation. Data may be analyzed in terms of four possible complex formalisms, the impedance $Z^{*}$, the electrical modulus $M^{*}$, the admittance $Y^{*}$ (or $A^{*}$ ), and the permittivity $\left(\varepsilon^{*}\right)$ [35]. These parameters are related according to the expressions [36-38]

$$
\begin{aligned}
Y^{*} & =\frac{1}{Z^{*}}, & M^{*} & =j \omega C_{0} Z^{*} \\
\varepsilon^{*} & =\frac{1}{M^{*}}, & Y^{*} & =j \omega C_{0} \varepsilon^{*},
\end{aligned}
$$

Complex permittivity $\varepsilon^{*}=\varepsilon^{\prime}-j \varepsilon^{\prime \prime}$,
Complex impedance $Z^{*}=Z^{\prime}-j Z^{\prime \prime}=\frac{1}{j \omega C_{o} \varepsilon^{*}}$

Complex modulus $M^{*}=M^{\prime}-j M^{\prime \prime}=\frac{1}{\varepsilon^{*}}=\frac{\varepsilon^{\prime}+j \varepsilon^{\prime \prime}}{\left(\varepsilon^{\prime}\right)^{2}+\left(\varepsilon^{\prime \prime}\right)^{2}}$

Complex admittance $Y^{*}=Y^{\prime}+j Y^{\prime \prime}=j \omega C_{o} \varepsilon^{*}$,

where $\omega$ is the angular frequency and $C_{o}=\varepsilon_{o}$ Se is the vacuum capacitance of the measuring cell. The use of the function $M^{*}$ is suitable for the resistive and/or capacitive analysis 


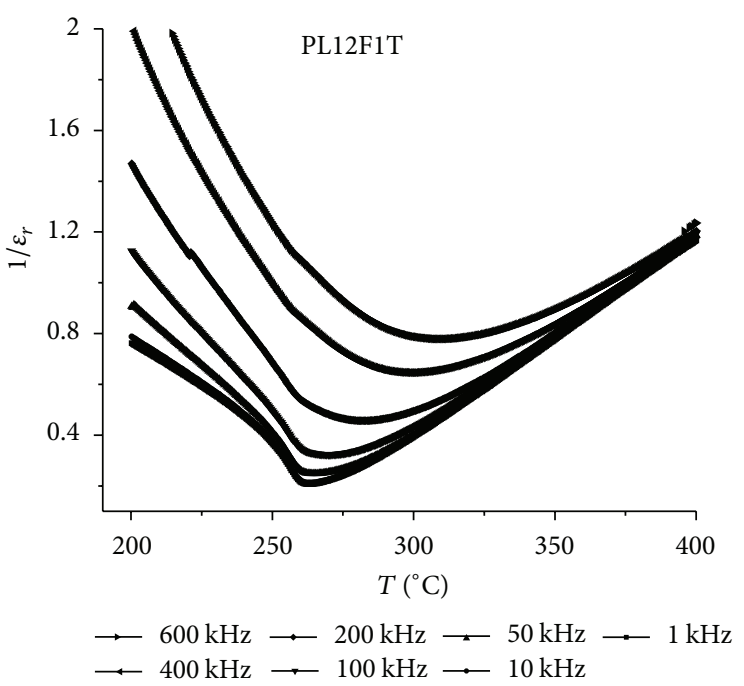

(a)

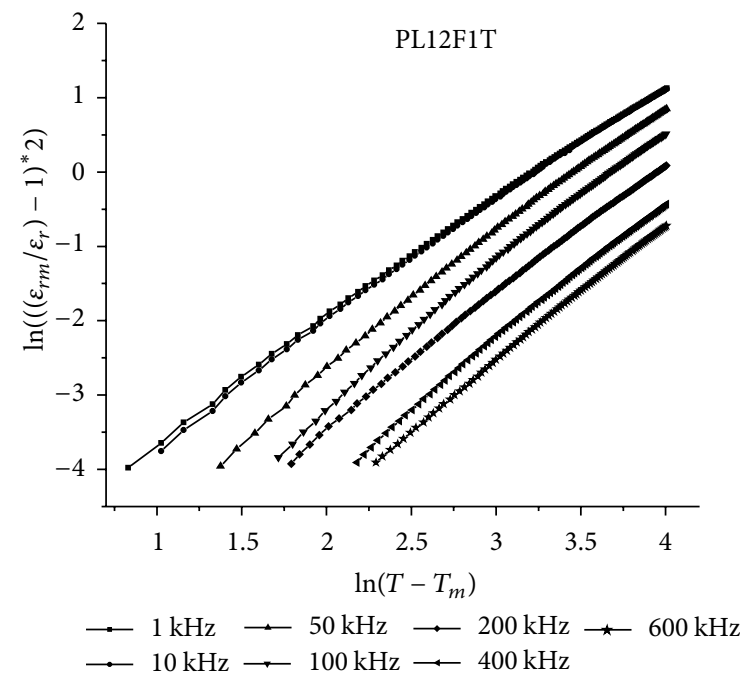

(c)

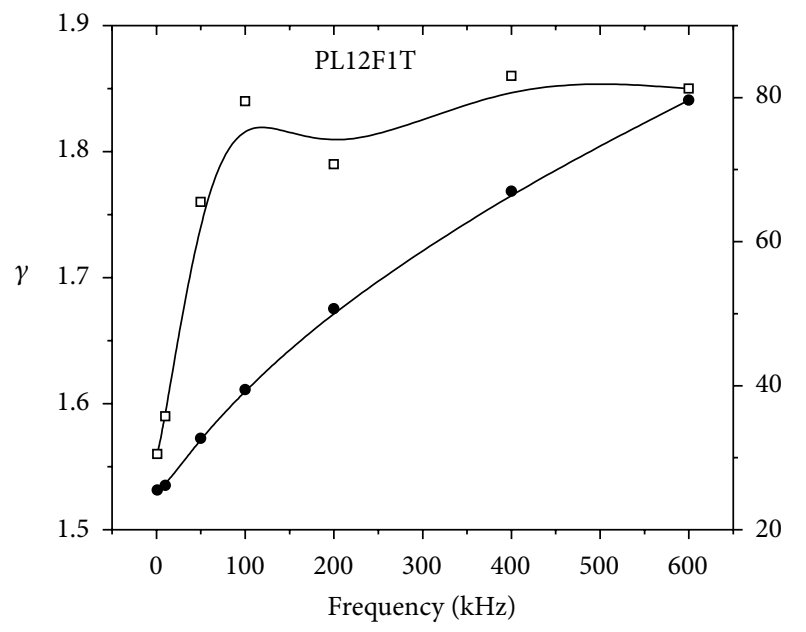

$\rightarrow \gamma$

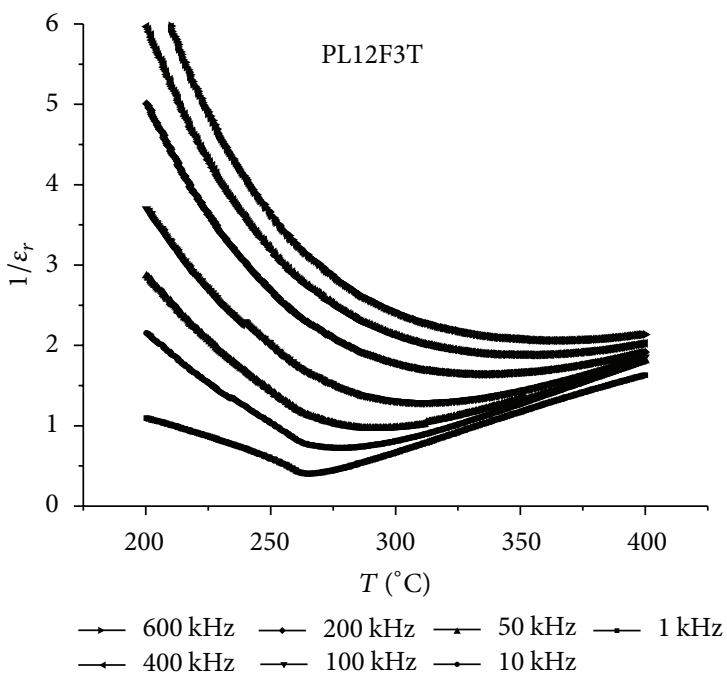

(b)

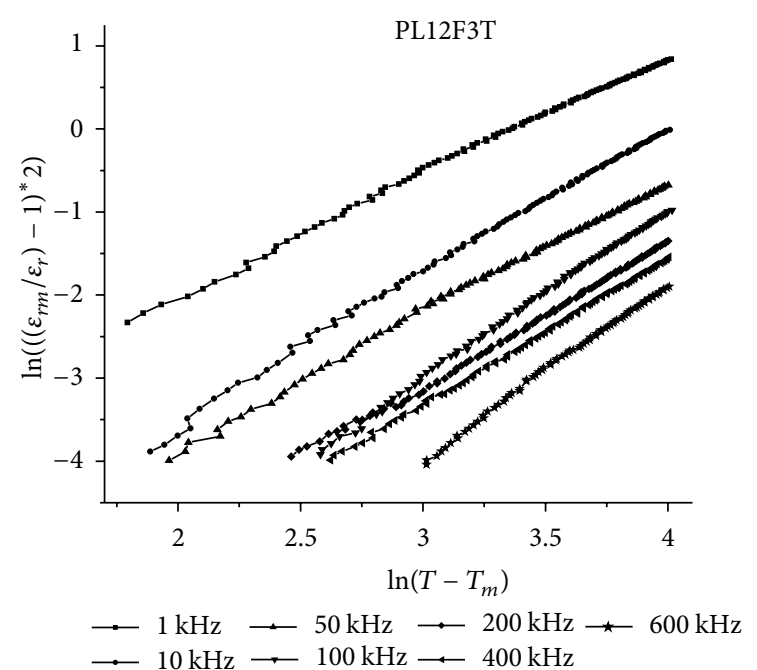

(d)

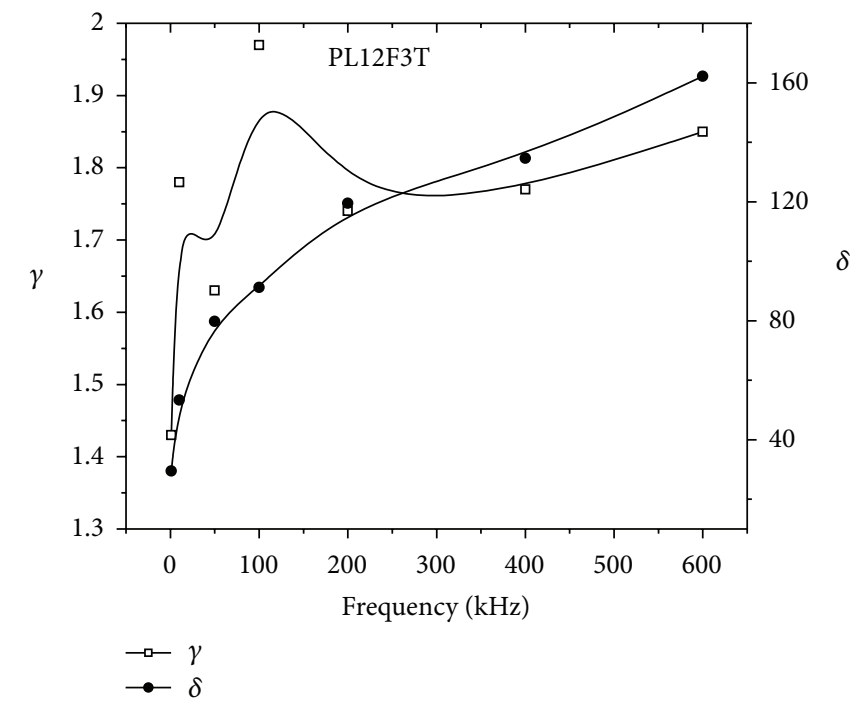

(f)

Figure 4: Curie-Weiss law ((a) and (b)) and modified Curie-Weiss law ((c) and (d)) of PLFT ceramics for different temperatures at $10 \mathrm{kHz}$. Relaxation and diffuseness parameters ((e) and (f), lines are given as eye guides). 


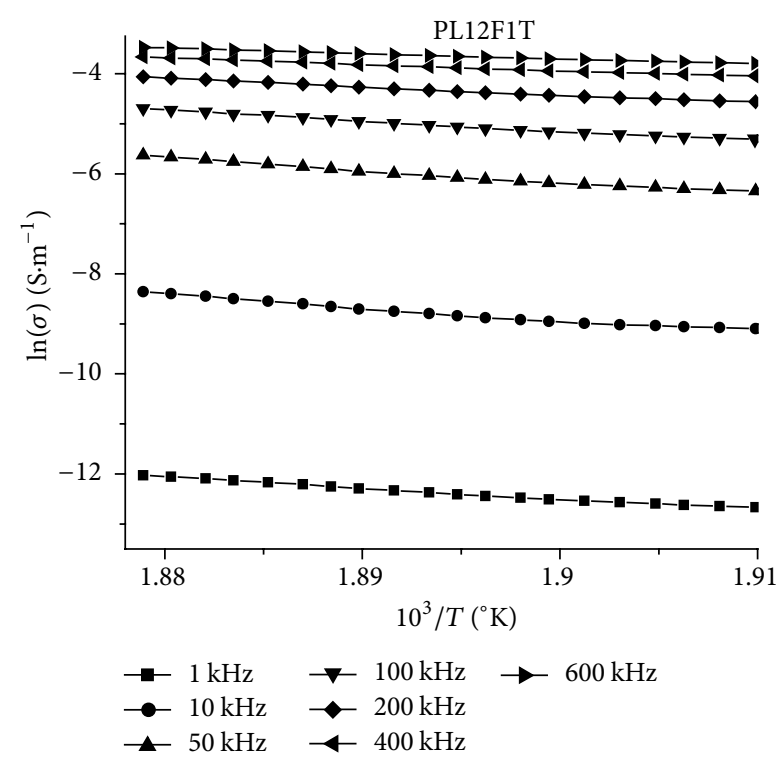

(a)

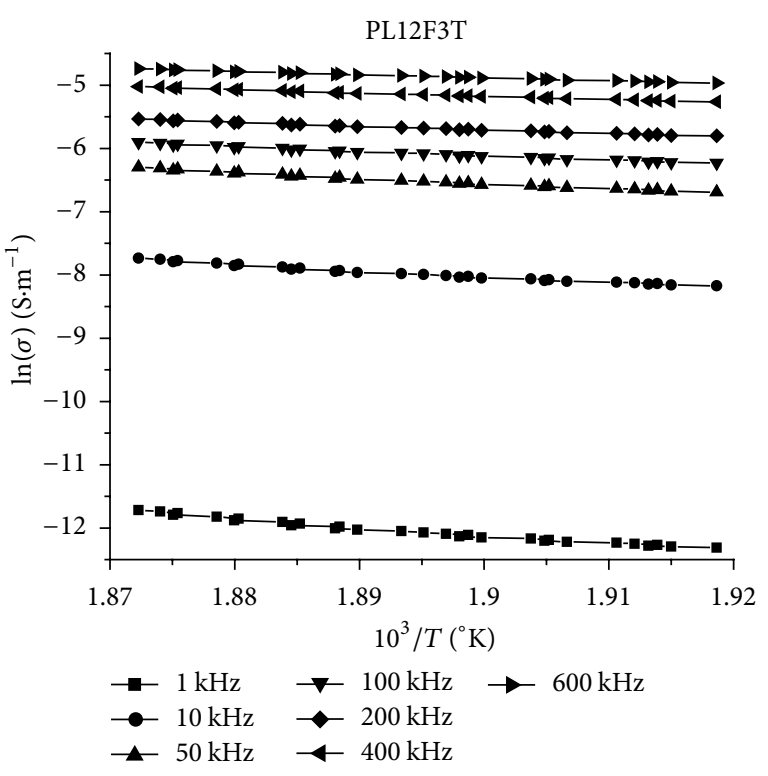

(b)

Figure 5: Plot of $\ln \left(\sigma_{\mathrm{dc}}\right)$ versus $10^{3} / T$ for PL12F $x$ T.

when localized relaxation dominates, while the $Z^{*}$ function is appropriate when the long-range conductivity dominates. In particular, the use of $Z^{*}$ formalism allows for a direct separation of the bulk, grain boundary, and electrode phenomena and also determination of each individual resistance [39]. From this formalism the electric loss is given by

$$
\tan \delta=\frac{\varepsilon^{\prime \prime}}{\varepsilon^{\prime}}=\frac{M^{\prime \prime}}{M^{\prime}}=\frac{Z^{\prime}}{Z^{\prime \prime}}=\frac{Y^{\prime}}{Y^{\prime \prime}} .
$$

Similar evolution of $\varepsilon^{\prime}, M^{\prime}, Z^{\prime \prime}$, and $Y^{\prime \prime}$ is expected and so is that of $\varepsilon^{\prime \prime}, M^{\prime \prime}, Z^{\prime}$, and $Y^{\prime}$. Thus, we have considered $\varepsilon^{\prime}$ and $\varepsilon^{\prime \prime}$ plots as function of frequency at various temperatures.

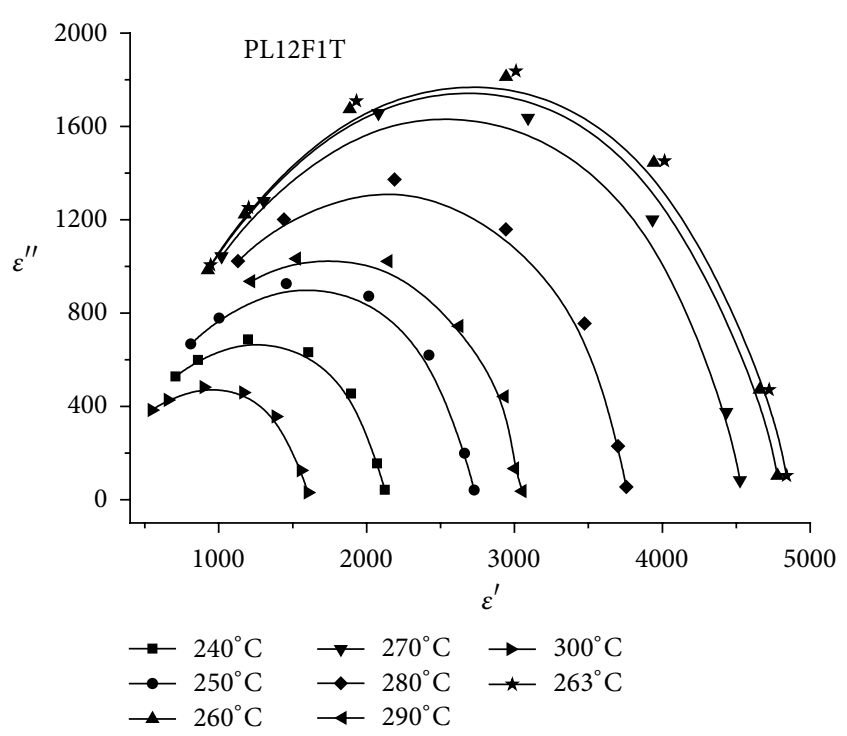

(a)

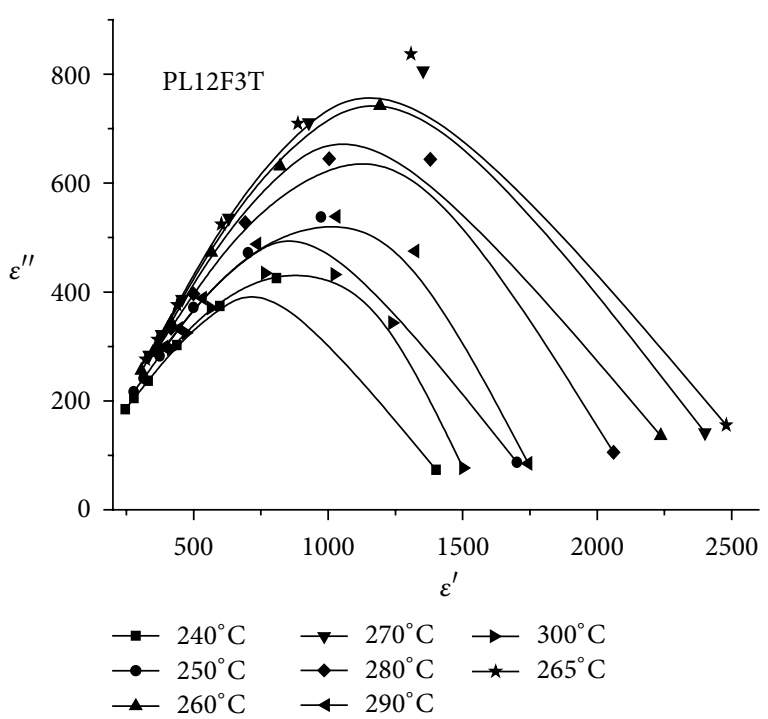

(b)

FIGURE 6: Complex permittivity spectra (Nyquist plots) for PLFT ceramics.

Complex modulus formalism is a very important and convenient tool to detect the bulk phenomena properties as apparent conductivity and relaxation times. It provides an insight into the electrical processes characterized by the smallest capacitance of the material [40]. The smallest semicircle in the Nyquist plot (i.e., $\varepsilon^{\prime \prime}$ versus $\varepsilon^{\prime}$ ) corresponds to the highest capacitance. In order to analyze and interpret experimental data, it is essential to have an equivalent circuit model that provides a realistic representation of the electrical properties.

Figure 6 shows complex permittivity spectra (Nyquist plots) for PLFT ceramics. The effect of temperature on impedance behavior is much important at higher temperatures. The pattern of permittivity spectrum is characterized by the presence of semicircular arcs at different temperatures. 
This may possibly be attributed to the presence of single electrical relaxation phenomena in the material under investigation [41]. The radius of the semicircular arc increases with increasing temperature to reach a maximum. The intercept of a semicircular arc with the real axis gives an estimation of sample resistance. The high-frequency dispersion curves are attributed to the bulk properties of the material and arise due to bulk phenomena, while the low-frequency semicircle has been assigned to the grain boundary conduction [42]. The bulk resistance decreases with increasing temperature. Thus, the bulk conductivity of the materials increases with temperature. This behavior is analogous to the negative temperature coefficient of resistance (NTCR) property which is a normal behavior of semiconductor. Each semicircle represents the contribution of a particular process (electrodes and contacts, grain boundaries) to the total impedance of the sample. Measured values in the form of Nyquist plots are rarely ideal semicircular. Most of the authors describe them as depressed semicircle with their center lying below the $x$-axis. This phenomenon is called non-Debye relaxation [43]. Thus in our investigation we can argue that PL12F1T shows a Debye relaxation while PL12F3T reveals a non-Debye relaxation.

Figure 7 shows the variation of the real part of the permittivity $\left(\varepsilon^{\prime}\right)$ as a function of frequency over a wide range of temperature for the two samples. The nature of variation shows a monotonous decrease in the value of $\varepsilon^{\prime}$ with increasing frequency. For $T>T_{m}$ the permittivity value is higher at lower temperatures in the low-frequency region and decreases gradually with increasing frequency. This observation may possibly be related to a lack of restoring force governing the mobility of charge carriers under the action of an induced electric field at higher temperatures. This behavior supports that as frequency increases each ion moves a shorter and shorter path of electric field until the electric field changes so rapidly that the ions only "rattle" within the confinement of their potential energy wells. It also indicates the long-range mobility of charge carriers [44]. Larger $\varepsilon^{\prime}$ values at lower frequency and temperature indicated larger effects of polarization. The decrease in $\varepsilon^{\prime}$ with rise in temperature and frequency also indicates a possibility of increase in the ac conductivity with increase in temperature and frequency. The merger of real part of permittivity $\left(\varepsilon^{\prime}\right)$ in the higher frequency domain for all temperatures indicates a possibility of the release of space charge as a result of lowering in the barrier properties of the material [45]. These results indicate that electrical conduction will increase with rise in temperature and the phenomenon is dependent on release of space charge.

Moreover, Figure 7 shows the variation of the imaginary part $\left(\varepsilon^{\prime \prime}\right)$ of the permittivity with frequency (i.e., loss spectrum) at different temperatures. A peak has been observed which further broadened with rise in temperature. The trend of variation of $\varepsilon^{\prime \prime}$ with frequency is typical of the presence of electrical relaxation phenomena in the materials which is temperature dependent. The asymmetric broadening of the peaks suggests the presence of electrical process in the materials with a spread of relaxation time [46]. The lowfrequency side of the peak represents the range of frequency in which charge carriers are mobile over long distances. The

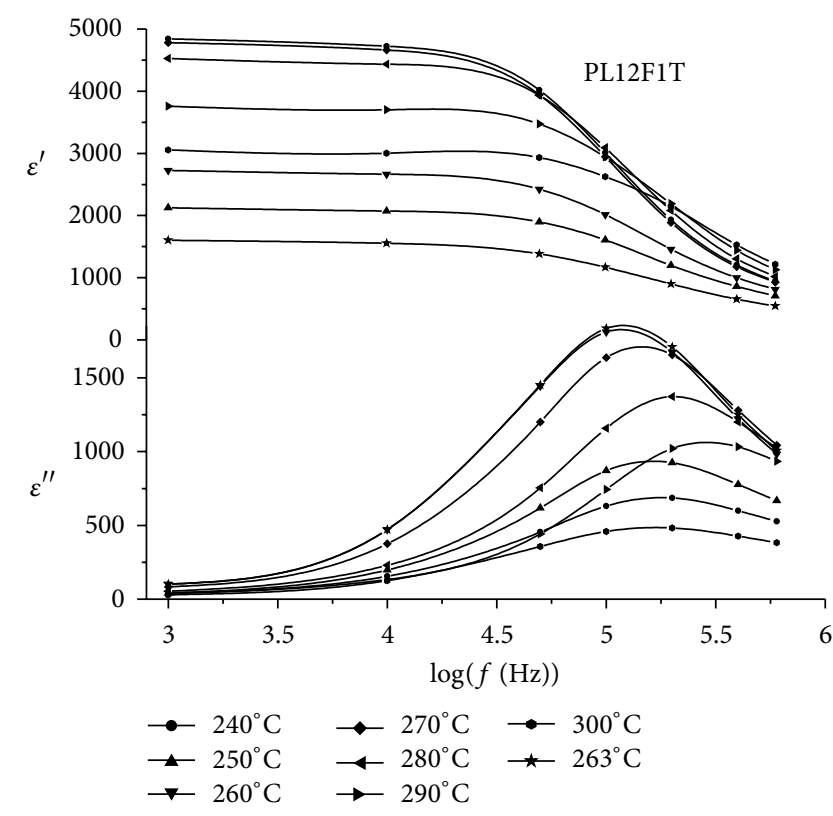

(a)

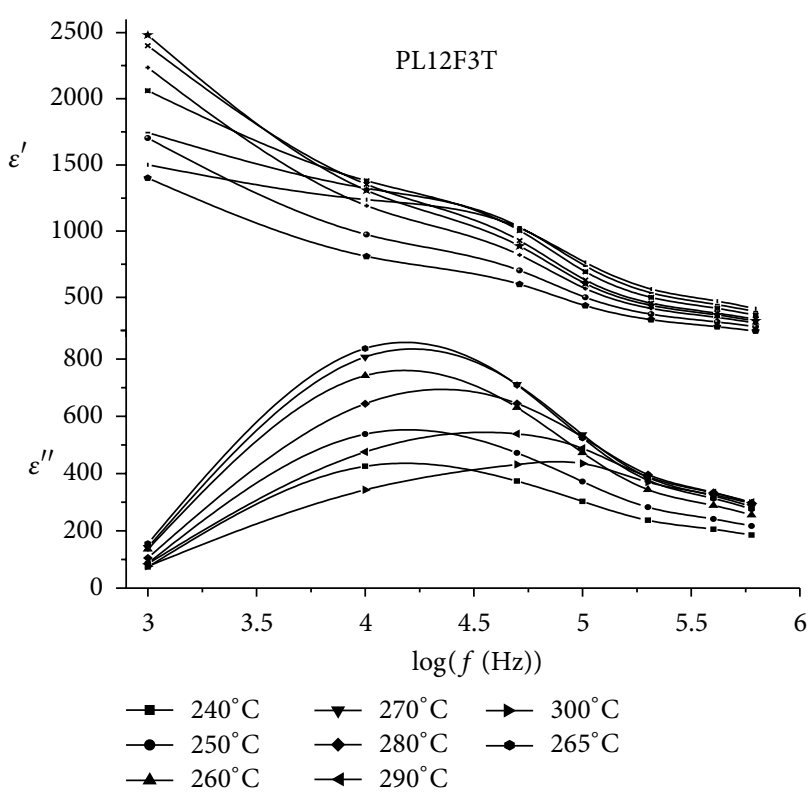

(b)

FIGURE 7: Variation of the real and imaginary part of the permittivity as a function of frequency.

higher frequency side of the $\varepsilon^{\prime \prime}$ peak represents the range of frequencies in which the ions are spatially confined to their potential wells and the ions can make only short-range motion within the well [47]. The region where the peak occurs is indicative of the transition from long-range to short-range mobility with increase in frequency. The behavior of the modulus spectrum is suggestive of temperature-dependent hopping type mechanism for electrical conduction (charge transport) in the system.

The shifting of peaks indicates that the net relaxation time is decreasing with the increase in temperature. In a 


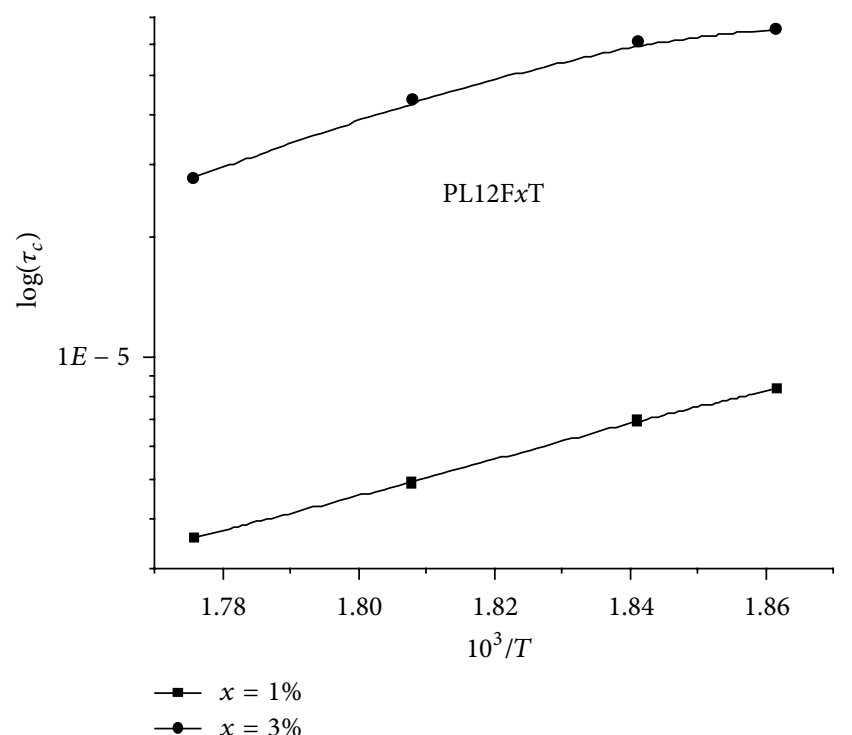

FIGURE 8: Linear relationship between the $\ln \left(\tau_{c}\right)$ and inverse temperature.

relaxation system, the conduction relaxation time $\left(\tau_{c}\right)$ can be estimated from $\varepsilon^{\prime \prime}$ versus $\log f$ plot using the relation: $\tau_{c}=$ $2 \pi / \omega=1 / f_{\max }$, where $f_{\max }$ is the relaxation frequency. Using a nonlinear fitting method, the experimental data can be well fitted by the Debye peak with a distribution in relaxation time and an exponential background $[48,49]$. Figure 7 displays the fitting results of the frequency dependence of the dielectric losses at various temperatures. It can be seen that the fitting lines almost pass all the experimental points, and only one Debye peak is observed. According to the fitting results, the relaxation strength increases, while $\tau_{c}$ decreases, with increasing temperature, which suggests a thermally activated process. The activation energy can be deduced from the Arrhenius law [50]: $\tau_{c}=\tau_{0} \exp \left(E_{a \tau c} / k_{B} T\right)$, where $\tau_{0}$ is the preexponential factor, $k_{B}$ is the Boltzmann constant, and $T$ is the absolute temperature. It is observed that the value of $\tau_{c}$ decreases with increase of temperature, which is a typical semiconductor behavior. It is clear that the value of activation energy decreases with an increase in Fe concentration. The small value of activation energy in PL12F1T may be due to the ionized oxygen vacancies. The insert of Figure 8 describes the linear relationship between the $\ln \left(\tau_{c}\right)$ and inverse temperature. From this figure, the relaxation parameter $\tau_{0}$ and the activation energy $E_{a \tau c}$ were evaluated and given in Table 1. $E_{a \tau c}$ is close to that for the diffusion of oxygen ions, suggesting that the dielectric relaxation process is associated with oxygen ion diffusion. Moreover, activation energy $E_{a \tau c}$ increases with Fe content. There may be a change in the concentration of oxygen vacancies due to the variable oxidation states of Fe.

\section{Conclusions}

$\mathrm{La}^{3+}$ and $\mathrm{Fe}^{3+}$ modified $\mathrm{PbTiO}_{3}$ (PLFT) compounds were prepared by sol-gel process using the colloidal destabilization method (DSC) followed by some heat treatments. Structural studies revealed that the structural phase of the compounds, after adding Fe ions, remained pseudocubic. According to SEM micrographs, the grain growth was suppressed in Fedoped samples, and a significant improvement in the density of the Fe-doped samples was observed. The temperature of transition from ferro- to paraelectric phase, $T_{m}$, decreased with Fe content, and the dielectric peak broadens (increase of the parameter $\delta$ ) showing the increase of the degree of diffusivity of the dielectric peak. In our investigation, the conductivity increases with temperature increase due to thermal activation of conducting species in all samples. With a further increase in the acceptor concentration, the conductivity becomes p-type and starts to decrease. Complex impedance spectroscopy, in terms of a simultaneous analysis of the complex permittivity, was used to investigate the electrical behavior of PLFT ceramics. From impedance data, semicircular arcs, corresponding to the electrical response of grains and grains boundary are clearly observed for the samples. The broader complex plots observed in samples are attributed to the random arrangement of cation in the structure, leading to microscopic heterogeneity in the composition. Complex impedance spectra indicate the possible contribution of the bulk and grain boundaries at higher temperatures and also the temperature-dependent relaxation phenomena. Measured values in the form of Nyquist plots are semicircular for PL12F1T, which demonstrates a Debye relaxation, and consist in depressed semicircles for PL12F3T revealing a non-Debye relaxation. With the help of the Arrhenius law, a linear relationship between the $\ln \left(\tau_{c}\right)$ and inverse temperature and the values of $E_{a \tau c}$ suggest that the dielectric relaxation process is associated with oxygen ion diffusion. Moreover, activation energy $E_{a}$ ic increases with Fe content, which may indicate a change in the concentration of oxygen vacancies due to the variable oxidation state of Fe.

\section{References}

[1] Z. Zhang, P. Wu, L. Lu, and C. Shu, "Electronic properties of A-site substituted lead zirconate titanate: density functional calculations," Physical Review B, vol. 76, Article ID 125102, 2007.

[2] C. H. Ahn, J. M. Triscone, and J. Mannhart, "Electric field effect in correlated oxide systems," Nature, vol. 424, no. 6952, pp. 10151018, 2003.

[3] C. Chandler, C. Roger, and M. H. Smith, "Chemical aspects of solution routes to perovskite-phase mixed-metal oxides from metal-organic precursors," Chemical Reviews, vol. 93, no. 3, pp. 1205-1241, 1993.

[4] G. Sheng, J. X. Zhang, Y. L. Li et al., "Domain stability of $\mathrm{PbTiO}_{3}$ thin films under anisotropic misfit strains: phase-field simulations," Journal of Applied Physics, vol. 104, no. 5, Article ID 054105, 2008.

[5] S. Sen, R. N. P. Choudhary, A. Tarafdar, and P. Pramanik, "Impedance spectroscopy study of strontium modified lead zirconate titanate ceramics," Journal of Applied Physics, vol. 99, no. 12, Article ID 124114, 2006.

[6] V. R. Palkar, J. John, and R. Pinto, "Observation of saturated polarization and dielectric anomaly in magnetoelectric $\mathrm{BiFeO}_{3}$ thin films," Applied Physics Letters, vol. 80, no. 9, p. 1628, 2002.

[7] P. Venkateswarlu, A. Laha, and S. B. Krupanidhi, "AC properties of laser ablated La-modified lead titanate thin films," Thin Solid Films, vol. 474, no. 1-2, pp. 1-9, 2005. 
[8] L. H. Omari, S. Sayouri, T. Lamcharfi, and L. Hajji, "Study of the dielectric behaviour of PLFT ceramics," Physical Chemistry News, vol. 64, pp. 6-11, 2012.

[9] A. Shukla, R. N. P. Choudhary, and A. K. Thakur, "Effect of $\mathrm{Mn}^{4+}$ substitution on thermal, structural, dielectric and impedance properties of lead titanate," Journal of Materials Science: Materials in Electronics, vol. 20, no. 8, pp. 745-755, 2009.

[10] D. K. Pradhan, B. K. Samantray, and R. N. P. Choudhary, "Complex impedance studies on a layered perovskite ceramic oxide$\mathrm{NaNdTiO}_{4}$," Materials Science and Engineering B, vol. 116, no. 1, pp. 7-13, 2005.

[11] O. Raymonds, R. Font, J. Portelles, and J. M. Siqueiros, "Frequency-temperature response of ferroelectromagnetic $\mathrm{Pb}\left(\mathrm{Fe}_{1 / 2} \mathrm{Nb}_{1 / 2}\right) \mathrm{O}_{3}$ ceramics obtained by different precursorspart II: impedance spectroscopy characterization," Journal of Applied Physics, vol. 97, no. 8, Article ID 084108, 8 pages, 2005.

[12] D. C. Sinclair and A. R. West, "Impedance and modulus spectroscopy of semiconducting $\mathrm{BaTiO}_{3}$ showing positive temperature coefficient of resistance," Journal of Applied Physics, vol. 66, no. 8, p. 3850, 1989.

[13] L. H. Omari, Materials science and industrials processes [Doctoral thesis], Faculty of Science Dhar Mahraz, Fès, Morocco, 2009.

[14] M. Kumar and K. L. Yadav, "Study of dielectric, magnetic, ferroelectric and magnetoelectric properties in the $\mathrm{PbMn}_{x} \mathrm{Ti}_{1-x} \mathrm{O}_{3}$ system at room temperature," Journal of Physics: Condensed Matter, vol. 19, no. 24, Article ID 242202, 2007.

[15] L. H. Omari, S. Sayouri, T. Lamcharfi et al., "Comportement magnétoélectrique dans les céramiques $\mathrm{PbTiO}_{3}$ dopées au $\mathrm{Fe}$ et/ou La," Journal of Catalysis and Materials Environment, vol. 7, pp. 405-409, 2009.

[16] L. H. Omari and S. Sayouri, Élaboration et Caractérisation de Céramique $\mathrm{PbLaFeTiO}_{3}$, Editions Universitaires Européennes, 2011.

[17] B. D. Cullity, Elements of X-Ray Diffraction, Addison-Wesley, Reading, Mass, USA, 2nd edition, 1978.

[18] H. P. Klung and L. B. Alexander, X-Ray Diffraction Procedures, Wiley, New York, NY, USA, 1974.

[19] J. K. Lee, K. S. Hong, C. K. Kim, and S. E. Park, "Phase transitions and dielectric properties in A-site ion substituted $\left(\mathrm{Na}_{1 / 2} \mathrm{Bi}_{1 / 2}\right) \mathrm{TiO}_{3}$ ceramics $(\mathrm{A}=\mathrm{Pb}$ and $\mathrm{Sr})$," Journal of Applied Physics, vol. 91, no. 7, p. 4538, 2002.

[20] B. K. Barick, R. N. P. Choudhary, and D. K. Pradhan, "Phase transition and electrical properties of lanthanum-modified sodium bismuth titanate," Materials Chemistry and Physics, vol. 132, no. 2-3, pp. 1007-1014, 2012.

[21] S. Yun, J. Shi, and X. Qian, "Defect-dipole-induced two important macroscopic effects: the dielectric relaxation and the ferroelectric aging in hybrid-doped $(\mathrm{Ba}, \mathrm{Ca}) \mathrm{TiO}_{3}$ ceramics," Materials Chemistry and Physics, vol. 133, no. 1, pp. 487-494, 2012.

[22] I. A. Santos and J. A. Eiras, "Phenomenological description of the diffuse phase transition in ferroelectrics," Journal of Physics: Condensed Matter, vol. 13, no. 50, pp. 11733-11740, 2001.

[23] M. Kellati, S. Sayouri, N. El Moudden, M. Elaatmani, A. Kaal, and M. Taibi, "Structural and dielectric properties of La-doped lead titanate ceramics," Materials Research Bulletin, vol. 39, no. 6, pp. 867-872, 2004.

[24] M. Kellati, N. El Moudden, A. Kaal, A. Elghazouali, and S. Sayouri, "Preparation and characterization of sol-gel derived Ladoped $\mathrm{PbTiO}_{3}$ ceramics," Annales de Chimie: Science des Materiaux, vol. 27, no. 1, pp. 43-50, 2002.
[25] K. Limame, M. Kellati, and S. Sayouri, "Relaxation and transport mechanisms in $\left(\mathrm{Pb}_{79} \mathrm{La}_{.21} \mathrm{Ti}_{95}\right) \mathrm{O}_{3}$ ceramic," Moroccan Journal of Condensed Matter, vol. 6, no. 1, 2005.

[26] J. d. L. S. Guerra, M. H. Lente, and J. A. Eiras, "Microwave dielectric dispersion process in perovskite ferroelectric systems," Applied Physics Letters, vol. 88, Article ID 102905, 3 pages, 2006.

[27] S. K. Rout, A. Hussian, J. S. Lee, I. W. Kim, and S. I. Woo, "Impedance spectroscopy and morphology of $\mathrm{SrBi}_{4} \mathrm{Ti}_{4} \mathrm{O}_{15}$ ceramics prepared by soft chemical method," Journal of Alloys and Compounds, vol. 477, no. 1-2, pp. 706-711, 2009.

[28] S. Anwar, P. R. Sagdeo, and N. P. Lalla, "Ferroelectric relaxor behavior in hafnium doped barium-titanate ceramic," Solid State Communications, vol. 138, no. 7, pp. 331-336, 2006.

[29] N. Vittayakorn, G. Rujijanagul, X. Tan, M. A. Marquardt, and D. P. Cann, "The morphotropic phase boundary and dielectric properties of the $\mathrm{xb}\left(\mathrm{Zr}_{1 / 2} \mathrm{Ti}_{1 / 2}\right) \mathrm{O}_{3}-(1-x) \mathrm{Pb}\left(\mathrm{Ni}_{1 / 3} \mathrm{Nb}_{2 / 3}\right) \mathrm{O}_{3}$ perovskite solid solution," Journal of Applied Physics, vol. 96, no. 9, pp. 5103-5110, 2004.

[30] H. T. Martirena and J. C. Burfoot, "Grain-size and pressure effects on the dielectric and piezoelectric properties of hotpressed PZT-5," Ferroelectrics, vol. 7, no. 1, pp. 151-152, 1974.

[31] V. M. Gurevich, Electric Conductivity of Ferroelectrics, Moskva, New York, NY, USA, 1969.

[32] S. Miga and K. Wojcik, "Investigation of the diffuse phase transition in PLZT X/65/35 ceramics, $X=7-10$," Ferroelectrics, vol. 100, no. 1, pp. 167-173, 1987.

[33] W. D. Kingery, Introduction to Ceramics, Wiley, New York, NY, USA, 1960.

[34] V. M. Gurevich, Electrical Conductivity of Ferroelectrics, Moskva, New York, NY, USA, 1969.

[35] E. J. Abram, D. C. Sinclair, and A. R. West, "A strategy for analysis and modelling of impedance spectroscopy data of electroceramics: doped lanthanum gallate," Journal of Electroceramics, vol. 10, no. 3, pp. 165-177, 2003.

[36] W. Cao and R. Gerhardt, "Calculation of various relaxation times and conductivity for a single dielectric relaxation process," Solid State Ionics, vol. 42, no. 3-4, pp. 213-221, 1990.

[37] R. Gerhardt, "Impedance and dielectric spectroscopy revisited: distinguishing localized relaxation from long-range conductivity," Journal of Physics and Chemistry of Solids, vol. 55, no. 12, pp. 1491-1506, 1994.

[38] M. Tomozawa, J. Cordaro, and M. Singh, "Low frequency dielectric relaxation from complex impedance and complex electric 'modulus,' Journal of Materials Science, vol. 14, no. 8, pp. 1945-1951, 1979.

[39] A. R. James, S. Priya, K. Uchino, and K. Srinivas, "Dielectric spectroscopy of $\mathrm{Pb}\left(\mathrm{Mg}_{1 / 3} \mathrm{Nb}_{2 / 3}\right) \mathrm{O}_{3}-\mathrm{PbTiO}_{3}$ single crystals," Journal of Applied Physics, vol. 90, no. 7, pp. 3504-3508, 2001.

[40] I. M. Hodge, M. D. Ingram, and A. R. West, "Impedance and modulus spectroscopy of polycrystalline solid electrolytes," Journal of Electroanalytical Chemistry and Interfacial Electrochemistry, vol. 74, no. 2, pp. 125-143, 1976.

[41] A. Molak, M. Paluch, S. Pawlus, J. Klimontko, Z. Ujma, and I. Gruszka, "Electric modulus approach to the analysis of electric relaxation in highly conducting $\left(\mathrm{Na}_{0.75} \mathrm{Bi}_{0.25}\right)\left(\mathrm{Mn}_{0.25} \mathrm{Nb}_{0.75}\right) \mathrm{O}_{3}$ ceramics," Journal of Physics D, vol. 38, no. 9, pp. 1450-1460, 2005.

[42] J. T. C. Irvine, D. C. Sinclair, and A. R. West, "Electroceramics: characterization by impedance spectroscopy," Advanced Materials, vol. 2, no. 3, pp. 132-138, 1990. 
[43] M. A. Alim, "Admittance-frequency response in zinc oxide varistor ceramics," Journal of the American Ceramic Society, vol. 72, no. 1, pp. 28-32, 1989.

[44] B. Behera, P. Nayak, and R. N. P. Choudhary, "Impedance spectroscopy study of $\mathrm{NaBa}_{2} \mathrm{~V}_{5} \mathrm{O}_{15}$ ceramic," Journal of Alloys and Compounds, vol. 436, no. 1-2, pp. 226-232, 2007.

[45] J. Maier, "Defect chemistry and ion transport in nanostructured materials-part II: aspects of nanoionics," Solid State Ionics, vol. 157, no. 1-4, pp. 327-334, 2003.

[46] R. Bharati, R. A. Singh, and B. M. Wanklyn, "On electrical transport in $\mathrm{CoWO}_{4}$ single crystals," Journal of Materials Science, vol. 16, no. 3, pp. 775-779, 1981.

[47] M. A. L. Nobre and S. J. Lanfredi, "Phase transition in sodium lithium niobate polycrystal: an overview based on impedance spectroscopy," Journal of Physics and Chemistry of Solids, vol. 62, no. 11, pp. 1999-2006, 2001.

[48] A. R. West, D. C. Sinclair, and N. Hirose, "Characterization of electrical materials, especially ferroelectrics, by impedance spectroscopy," Journal of Electroceramics, vol. 1, no. 1, pp. 65-71, 1997.

[49] W. D. Kingery, H. K. Bowen, and D. R. Uhlmann, Introduction to Ceramics, Wiley, New York, NY, USA, 1976.

[50] A. S. Nowick and B. S. Berry, An Elastic Relaxation in Crystalline Solids, chapter 2, Academic Press, New York, NY, USA, 1972. 

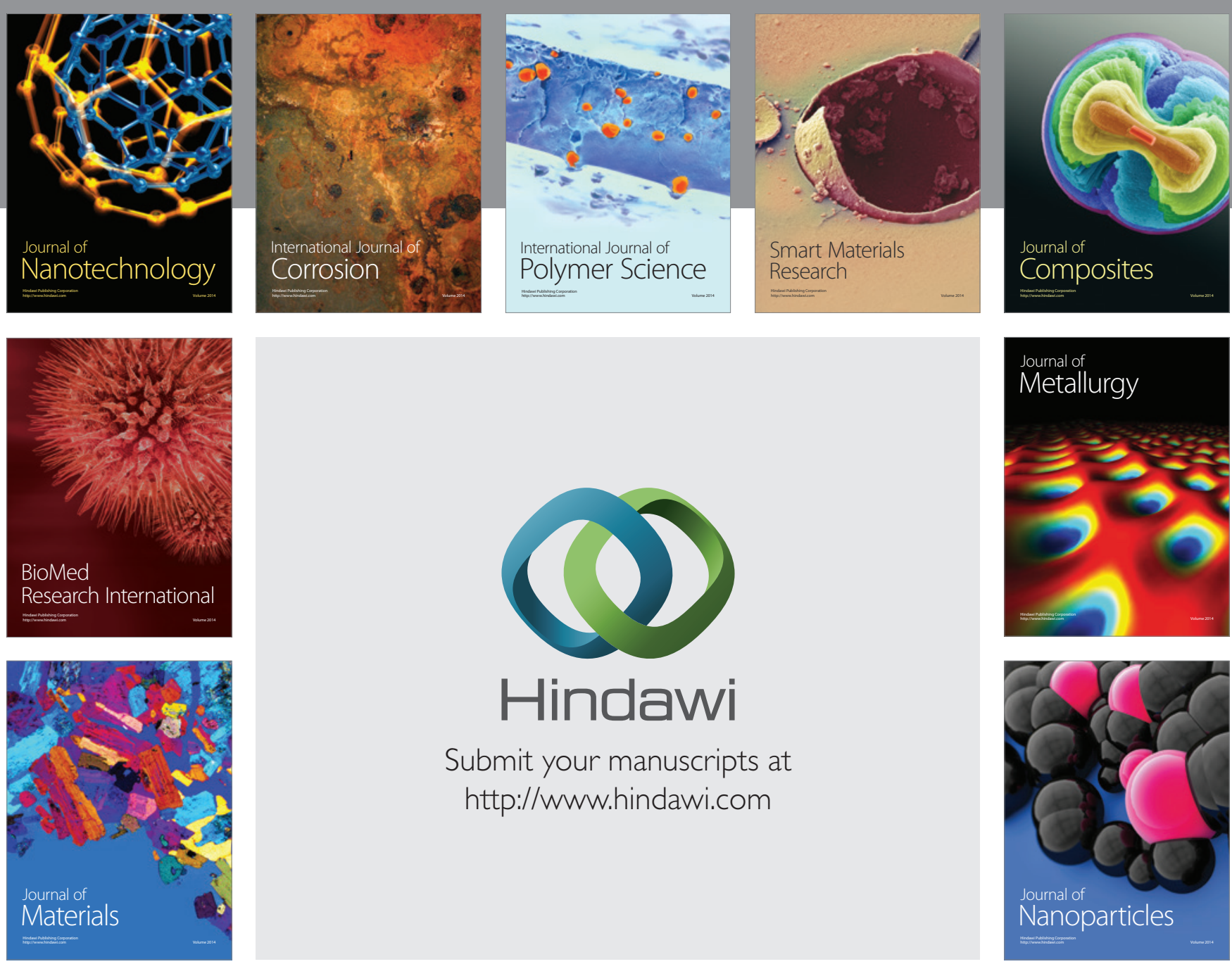

Submit your manuscripts at http://www.hindawi.com
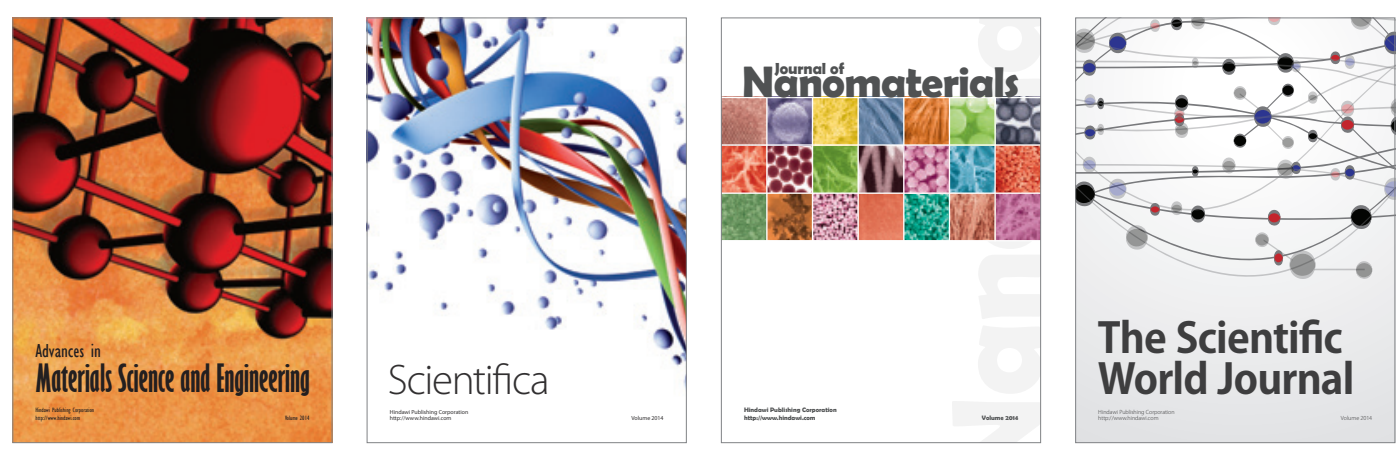

\section{The Scientific World Journal}
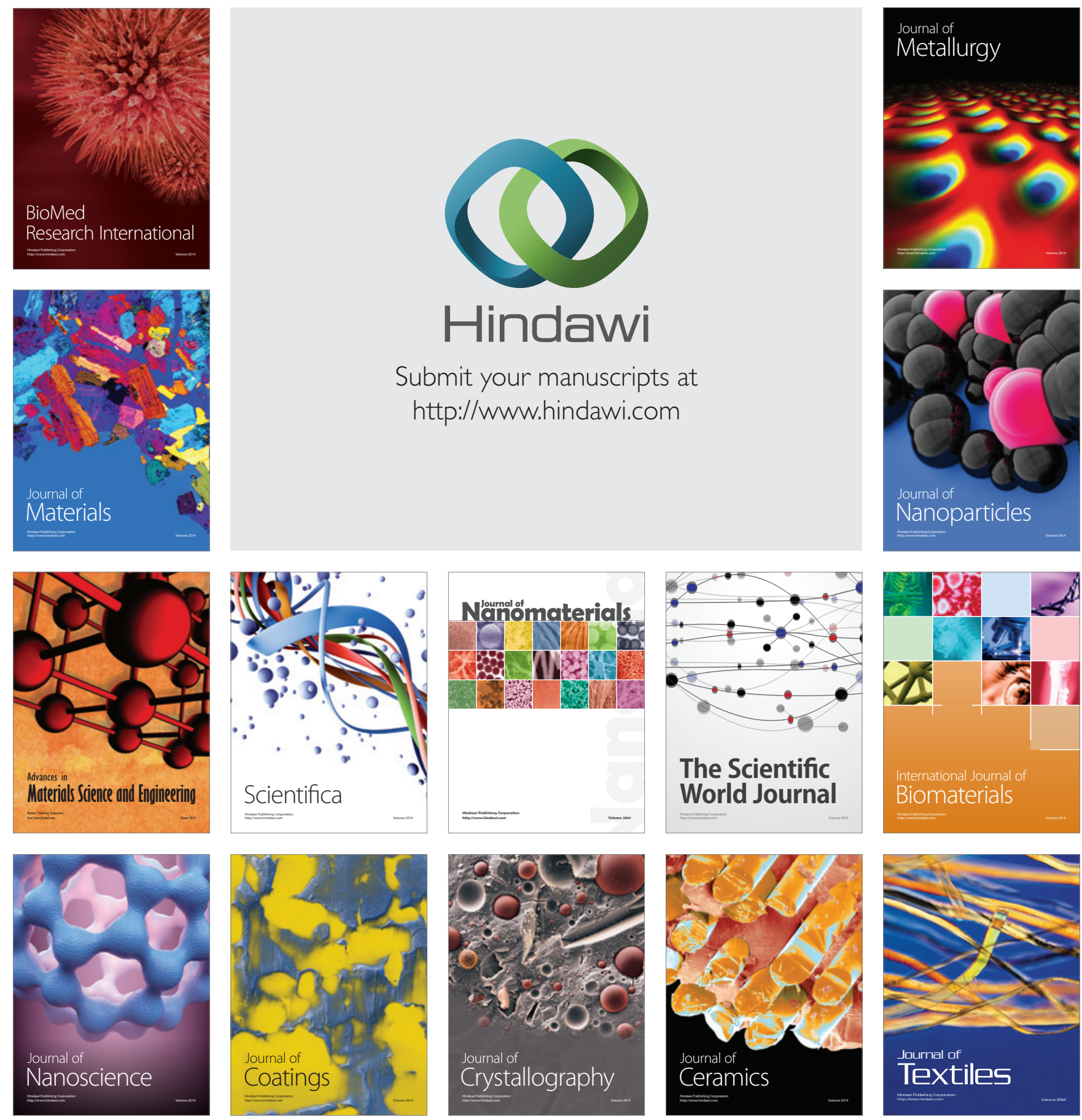